\title{
Nonconducting Polymers on Prussian Blue Modified Electrodes: Improvement of Selectivity and Stability of the Advanced $\mathrm{H}_{2} \mathrm{O}_{2}$ Transducer
}

\author{
Lilia V. Lukachova, Elena A. Kotel'nikova, Daniele D’Ottavi, Egor A. Shkerin, Elena E. Karyakina, Danila Moscone,
} Giuseppe Palleschi, Antonella Curulli, and Arkady A. Karyakin

\begin{abstract}
An approach to improve the analytical performance of a Prussian Blue (PB)-based hydrogen peroxide transducer is described. In support of this objective, both the stabilizing and anti-interferent properties of nonconducting films were used. Electropolymerization on the top surface of $\mathrm{PB}$ modified electrodes is possible due to the high oxidizing ability of Berlin Green, and the growth of nonconductive polymers may be independently monitored by investigating the redox activity of the inorganic polycrystal. The best performance characteristics, which are advantageous over existing $\mathrm{H}_{2} \mathrm{O}_{2}$ sensors, were obtained for PB electrodes covered with electropolymerized o-phenylenediamine (1,2-diaminobenzene). The reported transducer remained at the $100 \%$ response state for more than $20 \mathrm{~h}$ under continuous flow of $0.1-\mathrm{mM}$ hydrogen peroxide (flow rate $1 \mathrm{ml} \mathrm{min}^{-1}$ ), which improves the stability level among the selective $\mathrm{H}_{2} \mathrm{O}_{2}$ sensors by one order of magnitude. The selectivity factor of the PB-poly (1,2-diaminobenzene) based transducer relative to ascorbate is nominally 600. PB-poly(1,2-diaminobenzene) modified electrode allows the detection hydrogen peroxide in the flow-injection mode down to $10^{-7} \mathrm{M}$ with sensitivity of $0.3 \mathrm{~A} \mathrm{M}^{-1} \mathrm{~cm}^{-2}$, which is two times lower compared to the uncovered PB-based transducer.
\end{abstract}

Index Terms-Hydrogen peroxide, polymer, prussian blue (PB), sensor.

\section{INTRODUCTION}

$\mathbf{T}$ HE most common transducing principle for first generation oxidase-based biosensors is the detection of hydrogen peroxide, which is a product of the enzyme catalyzed reaction:

$$
\text { Analyte }+\mathrm{O}_{2} \stackrel{\text { oxidase }}{\longrightarrow} \text { Oxidized analyte }+\mathrm{H}_{2} \mathrm{O}_{2} \text {. }
$$

\footnotetext{
Manuscript received March 15, 2002; revised December 3, 2002. This work was supported in part by INTAS under Contract N 00-273 and in part by the Russian Foundation "Research and development for priority lines of science and technology" ("Biocatalytical technologies for chemical synthesis, analytical systems, and medicine"). The associate editor coordinating the review of this paper and approving it for publication was Dr. Michael V. Pishko.

L. V. Lukachova, E. A. Kotel'nikova, E. A. Shkerin, E. E. Karyakina, and A. A. Karyakin are with the Faculty of Chemistry, M. V. Lomonosov Moscow State University, Moscow, Russia (e-mail: lukachova@enzyme.chem.msu.ru; alenka@enzyme.chem.msu.ru; Ekaryakina@enzyme.chem.msu.ru; karyakin@chem.msu.ru).

D. D'Ottavi, D. Moscone, and G. Palleschi are with the Dipartimento di Scienze e Tecnologie Chimiche, Universita di Roma Tor Vergata, Rome, Italy (e-mail: ddottavi001@yahoo.it; danila.moscone@uniroma2.it; giuseppe.palleschi@uniroma2.it).

A. Curulli is with the Italian Centre of Research (CNR) di Studio per la Elettrochimica e la Chimica Fisica della Interfasi, Rome, Italy (e-mail: antonella.curulli@uniroma1.it).

Digital Object Identifier 10.1109/JSEN.2003.814646
}

The applications for these sensors include clinical diagnostics, environmental protection, and quality control in the food and pharmaceutical industries. Hydrogen peroxide itself is a toxic chemical agent present in rain and ground water that is a waste product of many industries and atomic power stations [1], [2]. In addition, hydrogen peroxide is used to disinfect water pools, food, and beverage packages [3], [4], which makes it important to measure its residual concentration.

Electrochemical detection of hydrogen peroxide can be carried out effectively on platinum or gold electrodes at a high anodic potential $(0.5-0.7 \mathrm{~V}, \mathrm{Ag} / \mathrm{AgCl})$. A variety of biosensors for glucose, lactate, glutamate, glycerol, piruvate, etc., were developed on this principle [5]-[9], having, however, the main disadvantage of low selectivity. Some substances presented in food and biological samples (e.g., ascorbate, urate, and acetaminophen) are efficiently oxidized in the same potential range and interfere with hydrogen peroxide detection. For example, the response to acetaminophen at $+0.65 \mathrm{~V}$ on a platinum electrode is even higher than the response to $\mathrm{H}_{2} \mathrm{O}_{2}$ [10]. The selectivity of hydrogen peroxide transducers relative to such reductants can be improved either using the alternative method for hydrogen peroxide detection (its reduction at low potentials rather than oxidation) or by covering the transducer with an additional permselective membrane.

The optimal potential range for biosensor operation is from -0.1 to $0.1 \mathrm{~V}(\mathrm{Ag} \mid \mathrm{AgCl})$, where unwanted reactions cause only a minor influence on biosensor response [11], [12]. Presently, there are only two transducers for hydrogen peroxide able to operate at such low potentials: peroxidase and Prussian Blue (PB) modified electrodes. The advantage of these transducers is the selective reduction of hydrogen peroxide in the presence of oxygen, which provides their ability to detect low levels of the analyte. PB is the most effective electrocatalyst for hydrogen peroxide reduction, and the corresponding modified electrodes are characterized by the electrochemical rate constant of $0.01 \mathrm{~cm} \mathrm{~s}^{-1}$ [13]. Sensitivities of PB modified electrodes, which were claimed to be the most advantageous $\mathrm{H}_{2} \mathrm{O}_{2}$ transducers [14], are around $1 \mathrm{~A} \mathrm{M}^{-1} \mathrm{~cm}^{-2}$ in the steady-state mode [14], [15]. Despite the fact that peroxidase electrodes are less effective electrocatalysts [16], [17], their similarly high sensitivities (recalculated per visible electrode area) can be achieved using rough surfaces with a roughness factor of approximately 10 (graphite) [18]. However, the stability of both types of electrodes is a crucial point, which limits their use in practice. 
Another problem is that, by decreasing the electrode potential, one can achieve a response to ascorbate, which is only ten times lower than the response of the biosensor to the specific analyte. However, in some cases, such as clinical diagnostics and food quality control, it is necessary to detect low levels of analytes in the presence of ascorbate, which is 10 to 100 times higher in concentration. Thus, the additional efforts in shielding the transducer surfaces with permselective membranes needs to be investigated.

Modification of the electrodes by both conducting and nonconducting polymers has been widely used to eliminate the interference effect. The advantages of films are their chemical and mechanical stability, ease of film formation procedure, and the possibility of immobilization of electroactive and/or bioactive species. Covering the electrode with Nafion [4], sol-gel [11], or other thick films [5] facilitated an increase in sensor selectivity by approximately ten times. Permselective properties are usually based on size exclusion or the electrostatic repulsion of the interferences. However, if the diffusion limitation of the substrate arises, the problem is a significant increase of the response time, and decreased sensitivity usually results.

Electrosynthesis of polymers compares favorably with the thick film method. Electrochemical control of the polymerization conditions is a common way to provide a uniform thin film with desirable properties. These processes can be accompanied by the immobilization of an enzyme from a neutral aqueous solution and, thus, satisfy the requirement for all-electrochemical sensor fabrication [19]. Nonconducting polymers usually produce more uniform films with limited thickness, while conducting films generate thick, porous surfaces with some additional sensing properties. In terms of selectivity to hydrogen peroxide in the presence of interferents, the most promising results were obtained with poly-1,2-diaminobenzene (poly-1,2-DAB) modified electrodes [20]. Deposition of (poly-1,2-DAB) films was found to cause only a minor reduction in its response to $\mathrm{H}_{2} \mathrm{O}_{2}$, whereas the noise signal of interferents was decreased five times [21].

We believed that the selectivity and stability of the PB-based hydrogen peroxide transducer could be further improved by the deposition of electro-inactive polymers on the top surface of the modified electrodes. The possibility for electropolymerization on the top surface of PB films was probably first shown in our publication [22] describing the high oxidizing ability of Berlin Green, the fully oxidized form of PB. Since that time, a variety of conducting and nonconducting polymers were synthesized on the top surface of transition metal hexacyanoferrate modified electrodes. In particular, constant potential deposition of poly-o-phenylenediamine (poly-1,2-diaminobenzene) over PB was recently carried out to immobilize glucose oxidase [23], [24].

In this paper, we report that the analytical performance of the PB-based hydrogen peroxide transducer can be remarkably improved by the deposition of an additional nonconductive polymer or sol-gel membrane on the top surface of a transition metal hexacyanoferrate modified electrode. The achieved 20 $\mathrm{h}$ of absolute operational stability under continuous flow of $0.1-\mathrm{mM}$ hydrogen peroxide and a selectivity factor 600 relative to ascorbate are advantageous over existing transducers.

\section{EXPERIMENTAL}

\section{A. Materials}

Experiments were carried out mainly with Millipore (MilliQ, USA) water. All inorganic salts and hydrochloric acid were analytical grade. Detection of hydrogen peroxide concentrations was made in phosphate buffer using both ordinary distilled and Millipore water.

Hydrogen peroxide (30\% solution, Reachim, Russia), 1,2-diaminobenzene (DAB) (Calbiochem, CA), catechol 99\% and uric acid (Sigma, Germany), L-ascorbic acid and acetaminophen, and D-(+)-glucose from ICN Biomedicals (USA) were used as received. Tetraethoxysilan (TEOS) was donated by Dr. S. A. Krutovertsev (JSC "Praktik NC," Zelenograd, Russia).

\section{B. Apparatus}

Galvanostatic and voltammetric studies were performed using a Solartron Schlumberger Electrochemical Interface Model 1286 (U.K.) connected to an IBM compatible personal computer for control and data acquisition. Experiments were carried out in a three-compartment electrochemical cell containing a platinum net auxiliary electrode and an $\mathrm{Ag} / \mathrm{AgCl}$ reference electrode in 1-M KCl. The cell construction allowed deaeration of the working electrode space. Glassy carbon (GC) disk electrodes (GC 2500, Research Institute of Graphite Materials, Moscow, Russia) with a diameter of $1.8 \mathrm{~mm}$ were used as working electrodes.

The flow-injection system contained a Cole Parmer (USA) peristaltic pump (7519-10), a homemade flow-through wall-jet cell with a $0.5-\mathrm{mm} \varnothing$ nozzle positioned $1 \mathrm{~mm}$ in front of the surface of the disk electrode, a homemade injector, and a Metrohm (Switzerland) potentiostat (641-VA). Some flow-injection experiments were performed using a Solartron Electrochemical Interface Model 1286 (UK).

\section{Procedures}

The working glassy carbon electrodes were polished with alumina powder $(0.3$ and $0.05 \mu \mathrm{m})$ to a mirror finish. The electrodes were then carefully rinsed with water and used immediately.

Electrodeposition of $\mathbf{P B}$ was carried out at constant cathodic current density of $80 \mu \mathrm{A} \mathrm{cm}{ }^{-2}$ for $50 \mathrm{~s}$ from an initial solution containing $4 \mathrm{mM} \mathrm{K}_{3}\left[\mathrm{Fe}(\mathrm{CN})_{6}\right]$ and $4 \mathrm{mM} \mathrm{FeCl}_{3}$ with $0.1 \mathrm{M}$ $\mathrm{KCl}$ and $0.1 \mathrm{M} \mathrm{HCl}$ as the supporting electrolyte. This method was found to give the PB modified electrodes an improved response to hydrogen peroxide and a decreased background current compared to the potentiostatic mode deposition used earlier [25]. After deposition of the PB films, the modified electrodes were activated in the same supporting electrolyte solution, which was used for film growth, by cycling the applied potential from -0.05 to $0.35 \mathrm{~V}$ at a sweep rate of $40 \mathrm{mV} \mathrm{s}^{-1}$ (20 cycles). The total amount of deposited PB $\left(6.5 \pm 0.5 \mathrm{nmol} \mathrm{cm}{ }^{-2}\right)$ was estimated from cyclic voltammograms. After first activation, the modified electrodes were heated for $1 \mathrm{~h}$ at $100^{\circ} \mathrm{C}$. For uncovered PB electrodes, the last step was the second activation in a $0.02 \mathrm{M}$ phosphate buffer $(\mathrm{pH}$ 6.0) with $0.1 \mathrm{M} \mathrm{KCl}$ by cycling at a sweep rate of $20 \mathrm{mV} \mathrm{s}^{-1}$ 
with the anodic switching potential in the range of $0.7-0.8$ V. Alternatively, after heating, the nonconducting polymers were deposited on the top surface of PB modified electrodes as described below.

Electrodeposition of poly(1,2-DAB) and polycatechol. After the first activation and heating cycle, the PB modified electrodes were placed in solution of DAB or catechol $(5-10 \mathrm{mM})$ in a $0.02-\mathrm{M}$ phosphate buffer with $0.1-\mathrm{M} \mathrm{KCl}$ as the supporting electrolyte (pH 6.0). Polymerization was carried out in a deaerated solution using cyclic voltammetric conditions with the anodic switching potential in the range of 0.7 to $0.8 \mathrm{~V}$ at a sweep rate of $20 \mathrm{mV} \mathrm{s}^{-1}$ (10-20 cycles).

Sol-gel modified electrodes. From 3 to $30 \mu \mathrm{L}$ of TEOS were added to $92 \%$ ethanol to a final volume of $3 \mathrm{~mL}$ and stirred carefully at a room temperature. Next, $3 \mu \mathrm{L}$ of hydrochloric acid $(0.1 \mathrm{v} / \mathrm{v} \%)$ were added as a catalyst. The resulting concentrations of TEOS were $0.1-1 \mathrm{v} / \mathrm{v} \%$. The solution was stored for 6 $\mathrm{h}$ for curing. Then, $5 \mu \mathrm{L}$ of sol was deposited on the top of the PB electrodes, which were spun $30 \mathrm{~min}$ at $1000 \mathrm{rpm}$. After that, the electrodes were heated at $115^{\circ} \mathrm{C}$ for $1 \mathrm{~h}$.

Analysis of hydrogen peroxide and interferences. The modified electrodes were poised to $0.0 \mathrm{~V}$ for $10 \mathrm{~min}$ to reach a constant baseline in the $0.05-\mathrm{M}$ phosphate buffer with $0.1-\mathrm{M} \mathrm{KCl}$ as the supporting electrolyte $(\mathrm{pH} \mathrm{6.0)}$. Hydrogen peroxide and interferences (ascorbic and uric acids and acetaminophen) were tested in both flow injection and continuous flow modes at flow rates of $1 \mathrm{~mL} \mathrm{~min}{ }^{-1}$.

\section{RESUlTS AND DISCUSSION}

\section{A. Electodeposition of Poly(1,2-DAB) and Polycatechol on the Top Surface of PB}

A variety of conditions have been reported for the electrodeposition of nonconductive polymers. In the great majority of publications, the cyclic voltammetric [26] or potentiostatic [19], [23], [27], [28] procedures have been described. The initial solutions usually contained millimolar concentrations of monomers in neutral phosphate or acetate buffer.

We decided to investigate aromatic amines and phenols as potential monomers for electrosynthesis of the shielding membranes. Based on the fact that electropolymerization of 1,2-diaminobenzene (o-phenylenediamine) and catechol provides attractive performance characteristics of the resulting biosensors [20], [21], [27], [28], these particular monomers were chosen for deposition onto the PB modified electrodes.

Fig. 1 presents cyclic voltammograms of the poly(1,2-DAB) electrosynthesis on the PB-modified glassy carbon electrode. Irreversible oxidation of the monomer (1,2-DAB) is observed at high anodic potentials $\sim 0.7 \mathrm{~V}$. In the course of continuous cycling, the peak of the monomer's irreversible oxidation is decreased because the poly $(1,2-\mathrm{DAB})$ membrane shields the electrode surface. In the first cycle, an additional anodic peak of monomer oxidation at $0.33 \mathrm{~V}$ occurs. This indicates that the hexacyanoferrate in PB oxidation state has already enough oxidizing ability to oxidize $o$-phenylenediamine. In further cycles, this peak disappears because the polymer film as formed shields the PB surface and blocks this reaction.

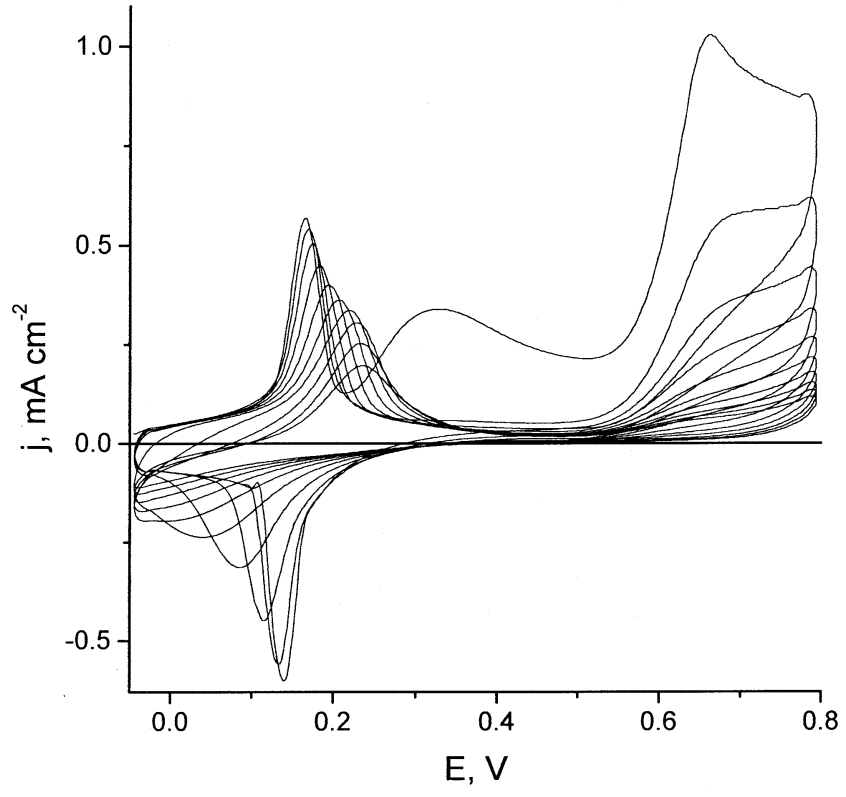

Fig. 1. Electropolymerization of 1,2-DAB on the top of a PB modified electrode: 5-mM DAB, 0.02-M phosphate $\mathrm{pH} 6.0$ with $0.1 \mathrm{M} \mathrm{KCl}, 20 \mathrm{mV} \mathrm{s}^{-1}$.

In contrast to the commonly used surfaces for the deposition of nonconductive polymers, PB modified electrodes have their own redox activity. Reduction of PB to Prussian White is accompanied with the consumption of alkali metal ions according to the reaction [29]

$\mathrm{Fe}_{4}{ }^{I I I}\left[\mathrm{Fe}^{I I}(\mathrm{CN})_{6}\right]_{3}+4 \bar{e}+4 K^{+} \longleftrightarrow K_{4} \mathrm{Fe}_{4}{ }^{I I}\left[\mathrm{Fe}^{I I}(\mathrm{CN})_{6}\right]_{3}$.

Since the cations cross the film-solution interface during oxidation-reduction, it is expected that the redox activity of PB is sensitive to the appearance of any film on its surface. Indeed, as seen in Fig. 1, in the course of 1,2-DAB electropolymerization, the PB peaks become broader, and the peak separation increases. Thus, the growth of nonconducting films onto the electroactive surfaces can be independently monitored.

Electropolymerization of poly(catechol) is similar to that of poly(1,2-DAB). Catechol has its own redox activity in the potential range investigated, which is observed over the PB set of peaks. This redox activity also decreases in the course of film growth.

\section{B. Analytical Characteristics of the PB Based Hydrogen Peroxide Transducers}

PB based transducers for hydrogen peroxide were tested under the continuous flow of either $\mathrm{H}_{2} \mathrm{O}_{2}$ or interferents at concentrations of $0.1 \mathrm{mM}$, as described in the Section II. Since uric acid and acetaminophen gave only a minor response even on uncovered PB electrodes, the detailed investigation of the transducers covered with nonconductive films was carried out with ascorbate.

The selectivity of the $\mathrm{H}_{2} \mathrm{O}_{2}$ transducer relative to ascorbate was characterized as a ratio of the current of hydrogen peroxide reduction to the current of interferent oxidation. As seen in Table I, the selectivity ratio of the traditionally deposited and post-treated PB modified electrodes is approximately 20. Surprisingly, treatment of the PB film at high anodic potentials re- 
TABLE I

Operational Characteristics of Hydrogen Peroxide TranCDucersUnder Continuous Flow $\left(1 \mathrm{~mL} \mathrm{~min}^{-1}\right.$ )

\begin{tabular}{l|c|c|c}
\hline & $\begin{array}{l}\text { Response to } \\
0.1 \mathrm{mM} \mathrm{H}_{2} \mathrm{O}_{2}, \mu \mathrm{A} \mathrm{cm}^{-2}\end{array}$ & $\begin{array}{l}\text { Selectivity relative } \\
\text { to ascorbate }\end{array}$ & $\begin{array}{l}\text { Time of } 100 \% \text { stability } \\
\text { under continuous flow of } \\
0.1 \mathrm{mM} \mathrm{H}_{2} \mathrm{O}_{2} \text {, hours }\end{array}$ \\
\hline PB & 120 & 20 & 0.5 \\
\hline PB-poly(catechol) & 75 & 90 & 0.6 \\
\hline PB-sol-gel & 35 & 210 & 3.5 \\
\hline PB-poly(1,2-DAB) & $\mathbf{6 0}$ & $\mathbf{6 0 0}$ & $>\mathbf{2 0}$ \\
\hline
\end{tabular}

sulted in a rise of sensor selectivity. When the modified electrodes were cycled in a neutral phosphate buffer solution up to potentials of $0.7-0.8 \mathrm{~V}$, the resulting selectivity reached the value of 80-90 (data not shown).

As a characteristic of operational stability, the time during which the transducer remained at the $100 \%$ response level under continuous flow of $0.1 \mathrm{mM}$ of hydrogen peroxide was chosen. The $100 \%$ response level means there is no visible decrease of the response. Under these experimental conditions (nozzle-to-

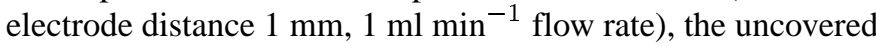
PB modified electrodes were completely stable, on average, for $0.5 \mathrm{~h}$ (Table I).

Electropolymerization of polycatechol films on the top surface of PB modified electrodes does not significantly improve the analytical performance of the transducer (Table I). Despite the selectivity of PB-poly(catechol) relative to ascorbate is increased, the similar rise in selectivity was observed for uncovered PB modified electrodes poised to high anodic potentials. The operational stability of the PB-poly(catechol) films was not improved, and the response to hydrogen peroxide was significantly lower compared to the uncovered transducer.

Electropolymerization of o-phenylenediamine on the top surface of the PB films, on the contrary, provides a dramatic improvement in the analytical performance of the hydrogen peroxide transducer, which is clearly seen in Table I. Selectivity of the PB-poly(1,2-DAB) sensor in relation to ascorbate is 30 times higher compared to the uncovered PB modified electrode; it reached an average value of 600 , which is significantly higher compared to the known transducers. The observed response to ascorbate did not exceed the baseline drift. For comparison, the response to ascorbate of the recently reported PB-poly(1,2DAB)-(glucose oxidase) electrode [23] was ten times higher $\left(10 \pm 1 \mathrm{~mA} \mathrm{M}^{-1} \mathrm{~cm}^{-2}\right.$ at applied potentials between -0.2 and $0.0 \mathrm{~V}$.

The most impressive improvement of the $\mathrm{H}_{2} \mathrm{O}_{2}$ sensor is its prolonged operational stability. Operational stability of the transition metal hexacyanoferrate electrode is a crucial point, which limits their practical applications. In addition, as was shown earlier [30], the product of hydrogen peroxide reduction on PB modified electrodes is the hydroxide anion $\left(\mathrm{OH}^{-}\right)$, which solubilizes the electrocatalyst. Thus, the operational stability of the PB modified electrodes in hydrogen peroxide reduction is extremely important.
Even after $20 \mathrm{~h}$ under continuous flow of 0.1-mM hydrogen peroxide, no decrease of the sensor response was observed. Since the operational stability of the uncovered PB films $(0.5$ $\mathrm{h}$ without decrease of the response) was already found to be comparative and even higher than that of the other known low-potential $\mathrm{H}_{2} \mathrm{O}_{2}$ transducers [14], the PB-poly(1,2-DAB) sensor improves the stability level among the selective peroxide sensors by one order of magnitude.

Selectivity to ascorbate and the operational stability of the $\mathrm{H}_{2} \mathrm{O}_{2}$ transducer are highly dependent on the growing conditions of poly(1,2-DAB), including the concentration of the monomer, the value of the anodic switching potential, and the number of cycles. Variation of growing conditions and, in particular, of the anodic switching potential obviously affects the morphology of the resulting nonconductive polymer film. To characterize the thickness of the nonconductive film, we have chosen the peak current of the PB redox activity. As seen in Fig. 1, the peak current decreases in the course of film growth. The ratio of the first cycle peak current to that of the last cycle characterizes film permeability to cations, which are required for PB electroactivity. The sensor selectivity in relation to ascorbate as a function of the peak current ratio is plotted in Fig. 2 . The filled symbol in Fig. 2 corresponds to the uncovered PB treated in the same electrochemical conditions used for film deposition. Solid line in Fig. 2 illustrate the general tendency observed in a number of experiments made under different conditions. As seen, the selectivity of the transducer increases as the permeability of the nonconductive film decreases. However, after reaching an optimal value of the peak current ratio at approximately $40-50 \%$, the sensor selectivity decreases as the film thickness is increased. This dependence of the selectivity on the permeability of the nonconducting film has to be taken into account in the course of sensor development.

As an alternative procedure for improving both selectivity and stability of the hydrogen peroxide transducer, the formation of sol-gel films on the top of the PB modified electrodes was used. Membranes, polymerized from $0.1 \mathrm{v} / \mathrm{v} \%$ sol (Table I), seemed to possess optimal characteristics in respect to the sensitivity and selectivity of the final hydrogen peroxide transducers. As observed, the remarkable improvement of the sensor characteristics can be achieved. The selectivity is increased ten times, but it is accompanied by an almost four times reduction of the re- 


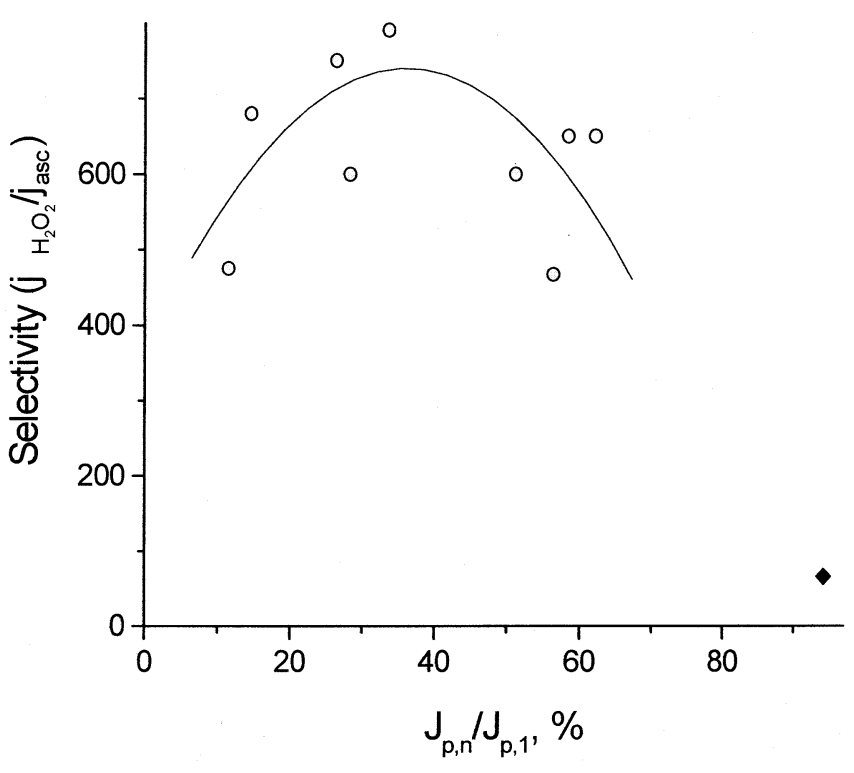

Fig. 2. Selectivity of the hydrogen peroxide transducer relative to ascorbate as a function of cation permeability of the nonconducting film (see text for details).

sponse to hydrogen peroxide. The operational stability of the sensor is also significantly improved. Thus, the sol-gel procedure can be used to improve the PB based transducer. However, the performance characteristics of the PB-poly(1,2-DAB) sensor are more attractive (Table I). Moreover, electropolymerization facilitates the synthesis of the more uniform nonconducting films.

It is interesting to compare the analytical performance of our PB-poly(1,2-DAB) sensor with other systems based on nonconductive films. Electropolymerization of $(1,2-\mathrm{DAB})$ on the surface of the platinum electrode has led to a seven-fold reduction of ascorbate interference [26]. Poly(1,2-DAB) film on the top surface of the PB modified electrode caused a similar seven-fold decrease in the response to ascorbate when compared with the PB films treated with the similar electrochemical regime used for deposition of the nonconducting film. Thus, the relative permeability of the poly(1,2-DAB) films electropolymerized on platinum and PB modified electrodes is quite similar. However, the initial selectivity of the PB electrodes is two orders of magnitude higher than that of platinum ones, which provides the highest selectivity level of the PB-poly(1,2-DAB) sensor.

Calibration graphs for hydrogen peroxide detection in the flow-injection mode are presented in Fig. 3. Both sensors based on uncovered conventional $\mathrm{PB}$ and $\mathrm{PB}$-poly(1,2-DAB) give straight lines in logarithmic plots over four orders of magnitude of $\mathrm{H}_{2} \mathrm{O}_{2}$ concentration. Both transducers allow the detection of hydrogen peroxide down to $10^{-7} \mathrm{M}$ in the flow-injection mode. Sensitivity values calculated from the slopes of the straight lines presented in Fig. 3, for uncovered and poly(1,2-DAB) modified $\mathrm{PB}$ are $0.6 \mathrm{~A} \mathrm{M}^{-1} \mathrm{~cm}^{-2}$ and $0.3 \mathrm{~A} \mathrm{M}^{-1} \mathrm{~cm}^{-2}$, respectively. The ratio of the sensitivities is similar to the ratio of the steady-state responses for the same transducers (Table I).

\section{CONCLUSION}

We conclude that using electro-inactive polymer films can improve the analytical characteristics of the advanced PB-based

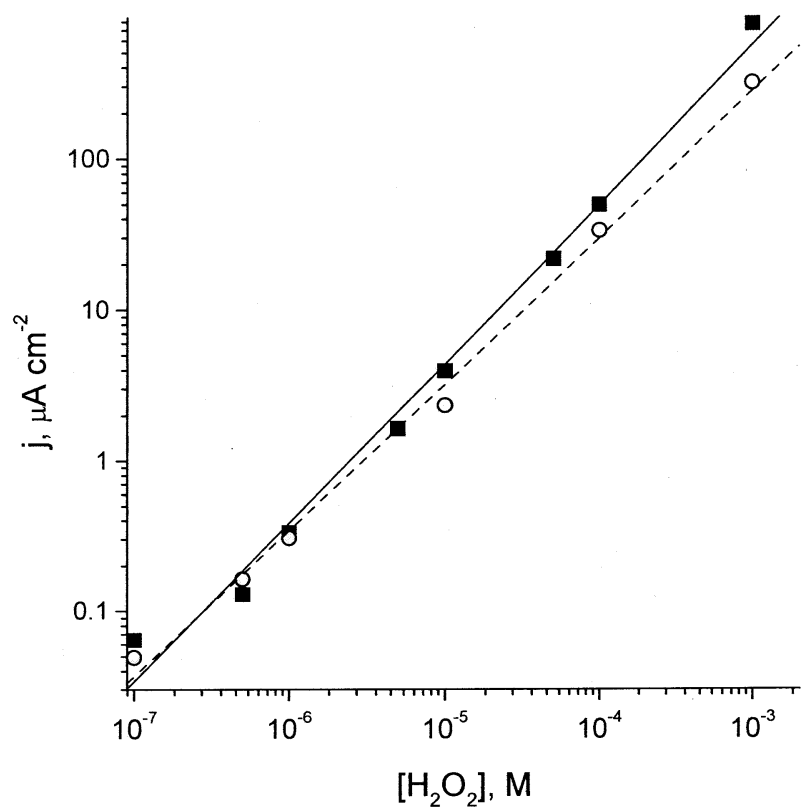

Fig. 3. Calibration plots for hydrogen peroxide detection in the flow-injection mode using (o)—PB-poly (1,2-DAB) and ( - - uncovered PB based transducers.

hydrogen peroxide transducer. Electropolymerization on the top of PB modified electrodes is quite possible due to the high oxidizing ability of Berlin Green, and the growth of nonconductive polymers can be independently controlled by observing the redox activity of the inorganic polycrystal. The permeability of the poly (1,2-DAB) films seems to be independent of this fact, whether they were electropolymerized on platinum or on $\mathrm{PB}$ modified electrodes.

The attractive performance characteristics of PB-poly (1,2-DAB) modified electrode are advantageous over existing $\mathrm{H}_{2} \mathrm{O}_{2}$ sensors. With this electrode design, the stability level among the selective peroxide sensors is improved by one order of magnitude. This particular sensor is considered as a ready-to-use device in analytical systems for continuous monitoring.

The selectivity of the PB-poly(1,2-DAB) based $\mathrm{H}_{2} \mathrm{O}_{2}$ transducer relative to ascorbate is approximately 600 , which is much higher compared to the other reported systems. This level of selectivity provides the possibility to develop the biosensor for use in certain areas of clinical diagnostics (brain research) and food control (juice and wine analysis), where detection of low levels of analytes in the presence of 10-100 higher concentrations of ascorbate is required.

Analytical characteristics, however, depend on the thickness of the nonconductive film. Selectivity of the transducer exhibits a strong dependence on cation permeability of the nonconducting films, which has to be taken into account in the course of sensor development.

\section{REFERENCES}

[1] W. Nowall and W. Kuhr, "Detection of hydrogen peroxide and other molecules of biological importance at an electrocatalytic surface on a carbon fiber microelectrode," Electroanal., vol. 9, pp. 102-109, 1997.

[2] Y. Wang, J. Huang, C. Zhang, J. Wei, and X. Zhou, "Determination of hydrogen peroxide in rainwater by using a polyaniline film and platinum particles co-modified carbon fiber microelectrode," Electroanal., vol. 10, pp. 776-778, 1998. 
[3] B. Strausak and W. Schoch, "Use of Hydrogen Peroxide for Desinfection of Swimming Pools," EP 0136973: Vol. bulletin 85/15, 1985.

[4] A. Schwake, B. Ross, and K. Cammann, "Chrono amperometric determination of hydrogen peroxide in swimming pool water using ultramicroelectrode array," Sens. Actuators B, vol. 46, pp. 242-248, 1998.

[5] Y. Sato, T. Sawaguchi, Y. Hirata, F. Mizutani, and S. Yabuki, "Glucose oxidase/polyion complex-bilayer membrane for elimination of electroactive interferents in amperometric glucose sensor," Anal Chim. Acta, vol. 364, pp. 173-179, 1998.

[6] S. Iijima, Y. Sato, T. Sawaguchi, and F. Mizutani, "Amperometric determination of piruvate, phosphate and urea using enzyme electrodes based on piruvate oxidase-containing poly(vinyl alcohol)/polyion complex-bilayer membrane," Electrochim. Acta, vol. 45, pp. 2945-2952, 2000.

[7] K. Cammann, A. Erlenkotter, G. Chemnitius, and N. Patel, "Fabrication and characterization of disposable type lactate oxidase sensors for dairy products and clinical analysis," Sens. Actuators B, vol. 67, pp. 134-141, 2000.

[8] D. Compagnone, M. Esti, M. Messia, E. Peluso, and G. Palleschi, "Development of a biosensor for monitoring glycerol during alcoholic fermentation," Biosens. Bioelectron., vol. 13, pp. 875-880, 1998.

[9] J. Cooper, P. Foreman, A. Glidle, T. Ling, and D. Pritchard, "Glutamate oxidase enzyme electrodes: microsensors for neurotransmitter determination using electrochemically polymerized permselective films," J. Electroanal. Chem., vol. 388, pp. 143-149, 1995.

[10] D. Daly and C. O'Sullivan, "The use of polymers coupled with metallised electrodes to allow $\mathrm{H} 2 \mathrm{O} 2$ detection in the presense of electrochemical interferences," Talanta, vol. 49, pp. 667-678, 1999.

[11] J. Wang, P. Pamidi, and D. Park, "Sol-gel-derived metal-dispersed carbon composite amperometric biosensors," Electroanal., vol. 9, pp. $52-55,1997$.

[12] L. Gorton, "Carbon paste electrodes modified with enzymes, tissues and cells," Electroanal., vol. 7, pp. 23-45, 1995.

[13] A. Karyakin, E. Karyakina, and L. Gorton, "The electrocatalytic activity of Prussian Blue in hydrogen peroxide reduction studied using a wall-jet electrode with continuous flow," J. Electroanal. Chem., vol. 456, pp. 97-104, 1998

[14] A. Karyakin, "Prussian Blue and its analogues: electrochemistry and analytical applications," Electroanalysis, vol. 13, pp. 813-819, 2001.

[15] A. Karyakin, E. Karyakina, and L. Gorton, "Amperometric biosensor for glutamate using Prussian Blue-based "artificial peroxldase" as a transducer for hydrogen peroxide," Anal. Chem., vol. 72, pp. 1720-1723, 2000.

[16] T. Ruzgas, L. Gorton, J. Emneus, and G. Marko-Varga, "Kinetic models of the action of HRP on graphite electrodes," J. Electroanal. Chem., vol. 391, p. 41, 1995.

[17] A. Lindgren, M. Tanaka, T. Ruzgas, L. Gorton, I. Gazaryan, K. Ishimori, and I. Morishima, "Direct electron transfer catalyzed by recombianant forms of horseradish peroxidase: insight into the mechanism," Electrochem. Commun., vol. 1, pp. 171-175, 1999.

[18] T. Ruzgas, E. Csöregi, J. Emnèus, L. Gorton, and G. Marko-Varga "Peroxidase-modified electrodes. Fundamentals and applications," Anal. Chim. Acta, vol. 330, pp. 123-138, 1996.

[19] M. Quinto, I. Losito, F. Palmisano, and C. Zambonin, "Disposable interference-free glucose sensor based on electropolymerized poly(pyrrole) permselective film," Anal. Chim. Acta, vol. 420, pp. 9-17, 2000.

[20] J. Lowry and R. O'Neill, "Partial characterization in vitro of glucose oxidase modified poly(phenylenediamine)-coated electrodes for neurochemical analysis in vivo," Electroanal., vol. 6, pp. 369-379, 1994.

[21] I. Carelli, I. Charotto, A. Curulli, and G. Palleschi, "Electropolymerization of hydroxybenzene and aminobenzene isomers on platinum electrodes to assemble interference-free electrochemical biosensors," Elec trochim. Acta, vol. 41, pp. 1793-1800, 1996

[22] A. Karyakin and M. Chaplin, "Polypyrrole-Prussian Blue films with controlled level of doping: codeposition of polypyrrole and Prussian Blue," J. Electroanal. Chem., vol. 370, pp. 301-303, 1994.

[23] R. Garjonyte and A. Malinauskas, "Amperometric glucose biosensor based on glucose oxidase immobilized in poly(o-phenylenediamine) layer," Sens. Actuators B, vol. 56, pp. 85-92, 1999.

[24] _ - "Glucose biosensor based on glucose oxidase immobilised in electropolymerized polypyrrole and poly(o-phenylenediamine) films on a Prussian Blue-modified electrode," Sens. Actuators B, vol. 63, pp. $122-128,2000$.

[25] I. Mattos, L. Gorton, T. Ruzgas, and A. Karyakin, "Sensor for hydrogen peroxide based on Prussian Blue modified electrode: improvement of the operational stability," Analytical Sci., vol. 16, pp. 1-5, 2000.
[26] A. Curulli and G. Palleschi, "Electropolymerization of pyrrole-2-carboxylic acid and 4,4'-dihydroxybenzophenone on platinum electrodes. Applications to assemble novel glucose sensors," Electroanal., vol. 9, pp. 1107-1112, 1997.

[27] C. Malitesta, F. Palmisano, L. Torsi, and P. Zambonin, "Glucose fast response amperometric sensor based on glucose oxidase immobilized in an electropolymerized poly(o-phenilenediamine) film," Anal. Chem., vol. 62, pp. 2735-2739, 1990.

[28] V. Sasso, R. Pierce, R. Walla, and A. Yacynych, "Electropolymerized 1,2-diaminobenzene as a means to prevent interferences and fouling and to stabilize immobilized enzymes in electrochemical biosensors," Anal. Chem., vol. 62, pp. 1111-1117, 1990.

[29] K. Itaya, I. Uchida, and V. Neff, "Electrochemistry of polynuclear transition metal cyanides: Prussian Blue and its analogues," Acc. Chem. Res. vol. 19, pp. 162-168, 1986

[30] A. Karyakin, E. Karyakina, and L. Gorton, "On the mechanism of $\mathrm{H} 2 \mathrm{O} 2$ reduction at Prussian Blue modified electrodes," Electrochem. Commun., vol. 1, pp. 78-82, 1999.

Lilia V. Lukachova graduated from Faculty of Chemistry, M. V. Lomonosov Moscow State University (MSU), Moscow, Russia, and received the Ph.D. degree in chemistry in 1995 .

Since 1999, she has been a Researcher with the Department of Chemical Enzymology, Faculty of Chemistry, MSU. She has published more than ten papers in international journals.

Elena A. Kotel'nikova received the Ph.D. degree in chemistry from the Faculty of Chemistry from M. V. Lomonosov Moscow State University (MSU), Moscow, Russia, in 2002.

During her Ph.D. studies, she was involved in research (through grants) on Prussian Blue biosensors development (INCO Project IC15CT980906 and INTAS Project 00-273). She published five papers on this subject.

Daniele D'Ottavi received the degree analytical chemistry from the University of Rome Tor Vergata, Rome, Italy, in 1998, with a thesis on the "Realization and application of amperometric and potentiometric microsensors for monitoring of biodegradation on stone surfaces in Roman hypogea."

Since 1999, he has been involved in a research program called the "Prussian Blue-based novel highly selective chemical and biological sensors for food control" (INCO-Copernicus Project). He has published several papers in national and international scientific journals on these subjects.

Egor A. Shkerin received the diploma from the Faculty of Chemistry, M. V Lomonosov Moscow State University (MSU), Moscow, Russia, in 2002. His work involved the electrosynthesis and properties of hydrogen peroxide transducer based on Prussian Blue modified electrodes.

Elena E. Karyakina is a Senior Researcher with the Department of Chemical Enzymology, Faculty of Chemistry, M. V. Lomonosov Moscow State University (MSU), Moscow, Russia. Her research interests include the development of novel chemical and biological sensors, nonaqueous enzymology approach for biosensor development, and hydrogenase-based hydrogen fuel electrodes. She published 45 papers, reviews, and patents in scientific journals.

Danila Moscone is an Associate Professor of analytical chemistry at the Chemical and Technology Department, University of Rome Tor Vergata, Rome, Italy. She has been involved in the field of biosensors for 20 years, and she is an expert in electrochemical biosensors and immunosensors assembling and their analytical evaluation. She is involved in the frame of projects funded by the European Community, in the development of immunosensors and interference-free biosensors based on screen printed electrodes (SPEs) in the field of environmental, clinical, and food analysis, and of microsensors for the assessment of conservation strategies in archaeological sites. Her scientific activity is summarized in more than 85 chapters in books, reviews, and papers in international and national scientific journals. She also acts as a referee for the international journals as Biosensors and Bioelectronics, Talanta, and Food Chemistry 
Giuseppe Palleschi received the Laurea Honoris Causa from the University of Bucharest, Bucharest, Romania, in 2000, for his activity in the area of chemical sensors for environment and food control.

He has been Head of the Department of Chemical Science and Technology, University of Rome Tor Vergata, Rome, Italy, since 1994. He is a Full Professor of analytical chemistry and coordinator of four European research projects. Over the last 20 years, he has been focused on the development of chemical sensors and bio- and immunosensors in the areas as biomedicine, food, and the environment. $\mathrm{He}$ is the author of more than 100 papers in international scientific journals.

Prof. Palleschi is a member of the Editorial Board of Analytical Letters, an Honorary Member of the Faculty of Chemistry, University of Bucharest, and member of the Scientific and Technical Committee for the protection of the sea and environment from pollutant substances caused by marine accidents, established by the Department of Civil Protection of the Ministry Council.
Antonella Curulli is a Researcher with the Italian Centre of Research (CNR) and Director of the Centro Studio CNR per l'Elettrochimica e la Chimica Fisica delle Interfasi, Rome, Italy. Her two main fields of research are organic electrosynthesis and the study and characterization of sensors and biosensors and related materials. She is the author of more than 50 papers, reviews, and chapters in books in the fields of design and application of sensors in clinical, food and environmental analysis, and related materials.

Arkady A. Karyakin received the Ph.D. and Doctor of Science degrees in chemistry from the Faculty of Chemistry, M. V. Lomonosov Moscow State University, Moscow, Russia (MSU), in 1985 and 1996, respectively.

$\mathrm{He}$ is a Leading Scientist and Head of the Laboratory of Biosensors and Biomolecular Electronics, Faculty of Chemistry, MSU. His research interests involve the development of novel chemical and biological sensors, elaboration of bio-fuel cells on the basis of fundamental research on enzyme bioelectrocatalysis, enzyme and antibody immobilization, conductive and nonconductive polymers, electroactive inorganic polycrystals and self-assembled multilayers, liquid-liquid interface, and material nano-structuring. He is the author of more then 70 papers and reviews in scientific journals. 